\title{
Effects of cysteine-containing compounds on biosynthesis of triacylglycerol and cholesterol and anti-oxidative protection in liver from mice consuming a high-fat diet
}

\author{
Chun-che $\operatorname{Lin}^{1}$ and Mei-chin $\mathrm{Yin}^{2} *$ \\ ${ }^{1}$ Department of Internal Medicine, Chung Shan Medical University Hospital, 110, Sec.1, Chien-Ku N Rd., Taichung City, \\ Taiwan, ROC \\ ${ }^{2}$ Department of Nutrition, China Medical University, 91, Hsueh-shih Rd., Taichung City, Taiwan, ROC
}

(Received 12 January 2007 - Revised 27 May 2007 - Accepted 31 May 2007)

Effects of $n$-acetyl cysteine (NAC), $s$-ethyl cysteine (SEC), $s$-propyl cysteine (SPC) and cysteine on enzymes participating in biosynthesis of TAG and cholesterol, and antioxidant protection in liver from mice consuming a high-saturated fat diet was examined. The high-fat diet provided $70 \%$ fat energy, in which saturated fat was $55 \%$ of total fat. NAC, SEC, SPC or cysteine, each agent at $1 \mathrm{~g} / \mathrm{l}$, was directly added into the drinking water as a supplement for 4 weeks. Results showed high saturated fat significantly increased hepatic TAG and total cholesterol contents $(P<0 \cdot 05)$ via enhancing the activity and mRNA expression of malic enzyme, fatty acid synthase and 3-hydroxy-3-methylglutaryl coenzyme A reductase $(P<0.05)$. The intake of NAC, SEC or SPC significantly decreased TAG and total cholesterol levels $(P<0.05)$ via lowering the activity and mRNA expression of these three lipogenic-related enzymes $(P<0.05)$. NAC, SEC or SPC treatment also significantly suppressed high saturated fat-induced hepatic mRNA expression of sterol regulatory element-binding protein (SREBP)-1c and SREBP-2 $(P<0 \cdot 05)$. High saturated fat decreased hepatic content of glutathione, and the activity of catalase and glutathione peroxidase $(P<0.05)$. The intake of NAC, SEC or SPC significantly increased hepatic glutathione content $(P<0.05)$, restored the activity and mRNA expression of glutathione peroxidase, and alleviated the high saturated fat-induced oxidative stress $(P<0 \cdot 05)$. These results support that NAC, SEC and SPC are potent agents for affecting hepatic biosynthesis of TAG and cholesterol, and protecting liver against high saturated fat-associated oxidative damage.

$s$-Ethyl cysteine: $s$-Propyl cysteine: Fatty acid synthase: HMG-CoA reductase: Sterol regulatory element-binding proteins: Glutathione peroxidase

$n$-Acetyl cysteine (NAC), $s$-ethyl cysteine (SEC) and $s$-propyl cysteine (SPC) are three hydrophilic cysteine-containing compounds naturally formed in Allium plants such as garlic and onion $^{1,2}$. Our previous study has observed that the intake of these three compounds effectively decreased high saturated fat-induced TAG and cholesterol accumulation in mice liver via reducing the activity of malic enzyme and fatty acid synthase (FAS), and the intake of these compounds also protected liver against high saturated fat-induced oxidative damage via enhancing glutathione peroxidase (GPx) activity ${ }^{3}$. In order to understand the molecular mechanism of these compounds, this present study examined the effects of these compounds on the mRNA expression of enzymes associated with biosynthesis of TAG and cholesterol, and anti-oxidative defence in mice liver.

On the other hand, sterol regulatory element-binding proteins (SREBP) are important transcription factors responsible for fatty acid and cholesterol metabolism ${ }^{4}$. It is known that three forms of SREBP, SREBP-1a, SREBP-1c and
SREBP-2, are expressed in organs such as liver, kidney and heart, in which SREBP-1c is more effective in modulating the expression of genes involved in fatty acid synthesis, whereas SREBP-2 is more predominant in modulating genes associated with cholesterol synthesis ${ }^{5,6}$. Therefore, the present study also examined the influence of these cysteine-containing compounds on the mRNA expression of these three SREBP in mice liver.

So far, it has been documented that cysteine, based on its auto-oxidation property and vascular toxicity, should be considered as a risk factor for $\mathrm{CVD}^{7,8}$. Our previous study also found that the presence of cysteine with high saturated fat enhanced TAG and cholesterol accumulation, and exhibited pro-oxidative effect in mice liver ${ }^{3}$. Apparently, the action mode of cysteine was different from other cysteine-containing compounds. In order to further understand the mode of action of cysteine, it is necessary to examine the impact of cysteine on the expression of lipogenic-related enzymes, SREBP or antioxidant enzymes.

Abbreviations: FAS, fatty acid synthase; GPx, glutathione peroxidase; GSH, glutathione; HMG-CoA, 3-hydroxy-3-methylglutaryl coenzyme A; NAC, $n$-acetyl cysteine; SEC, $s$-ethyl cysteine; SPC, $s$-propyl cysteine; SREBP, sterol regulatory element-binding protein; TC, total cholesterol.

*Corresponding author: Dr Mei-chin Yin, fax +886 4 24739030, email mcyin@csmu.edu.tw 
The major purpose of the present study was to investigate the effects of NAC, SEC and SPC on mRNA expression of lipogenic-related enzymes, SREBP and antioxidant enzymes in liver from mice consuming a high-saturated fat diet. The present study also provided information regarding the adverse effect of cysteine on lipid metabolism and oxidative damage.

\section{Materials and methods}

\section{Chemicals}

NAC (99\%), SEC (99.5\%) and cysteine (99\%) were purchased from Sigma Chemical Co. (St Louis, MO, USA). SPC (99\%) was supplied by Wakunaga Pharmaceutical Co. (Hiroshima, Japan).

\section{Animals and diet}

Male C57BL/6 mice (3-4 weeks old) were obtained from the National Laboratory Animal Center (National Science Council, Taipei City, Taiwan). Mice were housed on a $12 \mathrm{~h}$ light/ $12 \mathrm{~h}$ dark schedule, and fed with water and mouse standard diet for a 1-week acclimation period. Mice were then divided into two groups, one continuously consumed normal diet, and the other was switched to a high-fat diet containing $70 \%$ fat energy (Research Diet D12492; Research Diets, New Brunswick, NJ, USA), in which saturated and monounsaturated fats were 55 and $35 \%$ of total fat, respectively. Use of the mice was reviewed and approved by the Chung Shan Medical University animal care committee.

\section{Experimental design}

The normal diet group and the high-fat diet group were further divided into five sub-groups, in which water or each of four cysteine-containing compounds was supplied. NAC, SEC, SPC or cysteine, each agent at $1 \mathrm{~g} / \mathrm{l}$, was directly added into the drinking water. Body weight was measured every week. After 4 weeks, mice were killed with carbon dioxide. Liver from each mouse was collected and weighted. Then, $0 \cdot 2 \mathrm{~g}$ liver tissue was homogenized in $4 \mathrm{ml}$ PBS ( $\mathrm{pH} \mathrm{7.2)}$ ) on ice, and the homogenate was collected. After filtration through a filter paper (No. 1), the protein concentration of filtrate was determined by the method of Lowry et al. ${ }^{9}$ using bovine serine albumin as a standard. In all experiments, the sample was diluted to a final concentration of $1 \mathrm{mg}$ protein $/ \mathrm{ml}$.

\section{$T A G$ and total cholesterol determination}

The method described in Miura et al. ${ }^{10}$ was used to measure hepatic TAG and total cholesterol (TC) content. Briefly, $1 \mathrm{ml}$ liver filtrate was mixed with $2.5 \mathrm{ml}$ chloroform-methanol $(2: 1, v / v)$. The chloroform layer was collected and concentrated in a rotary evaporator and dried under a nitrogen stream. After adding $10 \%$ Triton X-100 in isopropanol, the sample was assayed with Wako Triglyceride E-Test and Total Cholesterol E-Test kits according to the manufacturer's instructions (Wako Pure Chemical, Osaka, Japan). Hepatic TAG and TC levels were expressed as $\mathrm{mg} / \mathrm{g}$ wet tissue.
Assay for the activity of malic enzyme, fatty acid synthase and 3-hydroxy-3-methylglutaryl coenzyme A reductase

The activity of malic enzyme and FAS was measured according to the methods of Stelmanska et al. ${ }^{11}$ and Nepokroeff $e t$ al. ${ }^{12}$. Both were determined by spectrophotometric assays. FAS was determined from the rate of malonyl-CoA-dependent NADPH oxidation. The enzyme activity was calculated as nmol NADPH formed or oxidized/min per mg protein. 3-Hydroxy-3methylglutaryl coenzyme A (HMG-CoA) reductase activity in liver filtrate was measured by a radiochemical method as described in Kita et al. ${ }^{13}$, in which $\left[3-{ }^{14} \mathrm{C}\right] \mathrm{HMG}-\mathrm{Co} \mathrm{A}$ was used as a substrate, and $\left[3-{ }^{14} \mathrm{C}\right]$ mevalonone synthesized during the assay was isolated by anion-exchange column chromatography.

\section{Lipid oxidation and glutathione determination}

Liver lipid oxidation was determined by measuring the level of malondialdehyde (nmol/mg protein) via an HPLC method $^{14}$. Briefly, $0.2 \mathrm{ml}$ liver filtrate was suspended in $0.8 \mathrm{ml}$ PBS. Then, $0.5 \mathrm{ml}$ TCA $(30 \%)$ was added. After vortexing and standing in ice for $2 \mathrm{~h}$, sample was centrifuged at $2000 \mathrm{~g}$ for $15 \mathrm{~min}$. Supernatant $(1 \mathrm{ml})$ was mixed with $0.25 \mathrm{ml}$ thiobarbituric acid $(1 \%)$ and the mixture was kept in a boiling water-bath for $15 \mathrm{~min}$. The concentration of malondialdehyde-TBA complex was assayed using HPLC equipped with a reverse-phase Shodex KC-812 column with the UV-Vis detector at $532 \mathrm{~nm}$. The glutathione (GSH) concentration (nmol/mg protein) in liver was determined by a colorimetric GSH kit (Oxis Research, Portland, OR, USA) according to the manufacture's instruction.

\section{Catalase and glutathione peroxidase assay}

Catalase and GPx activities (U/mg protein) in liver were determined by commercial catalase and GPx assay kits (Calbiochem, EMD Biosciences, San Diego, CA, USA). For thet catalase activity assay, liver filtrate was mixed with $10 \mathrm{~mm}-\mathrm{H}_{2} \mathrm{O}_{2}$ and $50 \mathrm{~mm}-\mathrm{PBS}$ (pH 7.2). The absorbance change at $240 \mathrm{~nm}$ during the time interval of $30 \mathrm{~s}$ was measured. GPx activity was measured indirectly by monitoring the consumption of NADPH at $340 \mathrm{~nm}$.

\section{Semi-quantitative PCR for $m R N A$ expression}

Part of the liver was homogenized in guanidine-thiocyanate, and total RNA was extracted according to the method of Kim et al. ${ }^{15}$. Total RNA $(2 \mu \mathrm{g})$ was used to generate cDNA, which was amplified using Taq DNA polymerase. PCR was carried out in $50 \mathrm{ml}$ reaction mixture containing Taq DNA polymerase buffer (20 mM-Tris- $\mathrm{HCl}, \mathrm{pH} 8.4,50 \mathrm{~mm}-\mathrm{KCl}$, $200 \mathrm{mM}$-dNTP, $2.5 \mathrm{~mm}-\mathrm{MgCl}_{2}, 0.5 \mathrm{~mm}$ of each primer) and $2.5 \mathrm{U}$ Taq DNA polymerase. The primers for PCR were synthesized based on previously published primer sequences ${ }^{4,15-17}$. Malic enzyme: forward, 5'-CCA CCA GCG CGG CTA CCT GCT GAC GCG GGA-3', reverse, 5'-CCT CTG ACT CGC CGG TGC CGC AGC CCG ATG-3'; FAS: forward, 5'-CAT GAC CTC GTG ATG AAC GTG T-3', reverse, 5'-CGG GTG AGG ACG TTT ACA AAG-3'; HMG-CoA reductase: forward, 5'-CCT GAC ACT 
GAA CTG AAG CG-3', reverse, 5'-TCT TTC CAG AAC ACA GCA CG-3'; SREBP-1a: forward, 5'-TAG TCC GAA GCC GGG TGG GCG CCG GCG CCAT-3', reverse, 5'-GAT GTC GTT CAA AAC CGC TGT GTG TCC AGT TC-3'; SREBP-1c: forward, 5'-ATC GGC GCG GAA GCT GTC GGG GTA GCG TC-3', reverse, 5'-ACT GTC TTG GTT GTT GAT GAG CTG GAG CAT-3'; SREBP-2: forward, 5'-CAT GGA CAC CCT CAC GGA GCT GGG CGA CGA-3' ${ }^{\prime}$, reverse, $5^{\prime}$-TGC ATC ATC CAA TAG AGG GCT TCC TGG CTC-3'; catalase: forward, 5'-AAC GCT GGA TGG ATT CTC CC- $3^{\prime}$, reverse, 5'-GCC CTA ACC TTT CAT TTC CCT TCA G-3'; GPx: forward, 5'-TTG GCT TGG TGA TTA CTG GC-3', reverse, 5'-CAT TAG GTG GAA AGG CAT CG-3'; $\beta$-actin: forward, 5'-ATG GAT GAC GAT ATC GCT GCG CTG G-3', reverse, 5'-GGT CAT CTT TTC ACG GTT GGC CTT AGG GT- $3^{\prime}$. The target concentration was expressed relative to the concentration of a reference housekeeping gene, $\beta$-actin. The cDNA was amplified under the following reaction conditions: for malic enzyme, FAS, HMG-CoA reductase, twenty-eight cycles consisting of denaturation at $94^{\circ} \mathrm{C}$ for $1 \mathrm{~min}$, annealing at $60^{\circ} \mathrm{C}$ for $1 \mathrm{~min}$ and extension at $72^{\circ} \mathrm{C}$ for $1 \mathrm{~min}$; for SREBP and $\beta$-actin, thirty-two cycles consisting of denaturation at $94^{\circ} \mathrm{C}$ for $40 \mathrm{~s}$, annealing at $68^{\circ} \mathrm{C}$ for $1 \mathrm{~min}$ and extension at $72^{\circ} \mathrm{C}$ for $2 \mathrm{~min}$; for $\mathrm{GPx}$ and catalase, twenty-four cycles consisting of denaturation at $94^{\circ} \mathrm{C}$ for $40 \mathrm{~s}$, annealing at $56^{\circ} \mathrm{C}$ for $20 \mathrm{~s}$ and extension at $70^{\circ} \mathrm{C}$ for $40 \mathrm{~s}$. The corresponding PCR products were analysed by $1 \%(\mathrm{w} / \mathrm{v})$ agarose gel electrophoresis and revealed with ethidium bromide. Finally, quantitative analysis was performed with a BAS 2000 BIO-image analyser (Fuji Photo Film Co., Tokyo, Japan). In the present study, mRNA level for each enzyme or SREBP of the normal diet group was defined as $100 \%$ for comparison.

\section{Statistical analyses}

The effect of each treatment was analysed from fifteen mice. Data were subjected to ANOVA and computed using the SAS General Linear Model procedure (Statistical Analysis Systems version 6; SAS Institute, Cary, NC, USA). Differences with $P<0.05$ were considered to be significant. Correlations between two variables were calculated by simple regression analysis (Minitab Inc., State College, Philadelphia, PA, USA)

\section{Results}

As shown in Table 1, the intake of these cysteine-containing compounds with normal diet did not affect body weight, water intake and feed intake $(P>0.05)$. When compared to normal diet groups, the high-fat diet significantly increased mice body weight. However, mice which consumed the high-fat diet with NAC, SEC or SPC had significantly lower body weight when compared to the high-fat diet with water group. The intake of these cysteine-containing compounds with normal diet did not affect hepatic TAG and TC levels (Table $2 ; P>0 \cdot 05$ ). When compared to normal diet groups, the high-fat diet significantly increased hepatic TAG and TC contents; however, the presence of NAC, SEC or SPC significantly decreased hepatic TAG and TC levels when compared with the water group.
Table 1. Body weight, water intake and feed intake in mice treated with normal diet or high-fat diet with water, $n$-acetyl cysteine (NAC), s-ethy cysteine (SEC), s-propyl cysteine (SPC) or cysteine (CYS)

(Mean values and standard deviations, $n$ 15)

\begin{tabular}{|c|c|c|c|c|c|c|c|c|}
\hline & \multicolumn{4}{|c|}{ Body weight (g) } & \multirow{2}{*}{\multicolumn{2}{|c|}{$\begin{array}{c}\text { Water } \\
\text { intake } \\
\text { (ml/mouse } \\
\text { per d) }\end{array}$}} & \multirow{2}{*}{\multicolumn{2}{|c|}{$\begin{array}{c}\text { Feed intake } \\
\text { (g/mouse } \\
\text { per d) }\end{array}$}} \\
\hline & \multicolumn{2}{|c|}{ Initial } & \multicolumn{2}{|c|}{ Final } & & & & \\
\hline & Mean & SD & Mean & SD & Mean & SD & Mean & SD \\
\hline \multicolumn{9}{|c|}{ Normal diet } \\
\hline Water & $16 \cdot 3$ & 0.5 & $24 \cdot 2^{*}$ & $1 \cdot 2$ & $4 \cdot 5^{\star}$ & 0.8 & $3 \cdot 3^{*}$ & \\
\hline NAC & $16 \cdot 0$ & 0.7 & $23 \cdot 9^{*}$ & 0.9 & $4 \cdot 2^{*}$ & 1.3 & $3 \cdot 6^{*}$ & 0 . \\
\hline SEC & $15 \cdot 9$ & 0.8 & $24 \cdot 5^{\star}$ & $1 \cdot 0$ & $4 \cdot 0^{*}$ & $1 \cdot 1$ & $3 \cdot 0^{*}$ & 0.7 \\
\hline SPC & $16 \cdot 4$ & 0.2 & $24 \cdot 0^{*}$ & $1 \cdot 1$ & $3 \cdot 8^{*}$ & $1 \cdot 2$ & $2 \cdot 8^{*}$ & 0.4 \\
\hline CYS & $16 \cdot 1$ & 0.4 & $23 \cdot 8^{*}$ & 1.5 & $4 \cdot 3^{*}$ & $1 \cdot 0$ & $3 \cdot 1^{*}$ & 0 \\
\hline \multicolumn{9}{|c|}{ High-fat diet } \\
\hline Water & $16 \cdot 4$ & 0.8 & $39.1 \dagger$ & $2 \cdot 1$ & $7 \cdot 7 \dagger$ & $1 \cdot 1$ & $5 \cdot 7 \dagger$ & \\
\hline NAC & $16 \cdot 1$ & 0.5 & $33 \cdot 2^{*} \dagger$ & 1.7 & $7.0 \dagger$ & 1.4 & $5.3 \dagger$ & 1.3 \\
\hline SEC & $16 \cdot 6$ & 0.6 & $33 \cdot 6^{*} \dagger$ & 1.5 & $6.8 \dagger$ & $1 \cdot 3$ & $5.4 \dagger$ & 1 . \\
\hline SPC & $16 \cdot 0$ & 0.6 & $32 \cdot 8^{*} \dagger$ & $1 \cdot 8$ & $6.3 \dagger$ & $1 \cdot 8$ & $5.6 \dagger$ & $1 \cdot 2$ \\
\hline CYS & $16 \cdot 5$ & 0.4 & 37.4 & $2 \cdot 3$ & $7 \cdot 2 \dagger$ & $1 \cdot 2$ & $5.4 \dagger$ & 1.2 \\
\hline
\end{tabular}

Mean values were significantly different from those of the high-fat diet with water group: ${ }^{*} P<0.05$.

Mean values were significantly different from those of the normal diet with water group: $\uparrow P<0.05$

The effect of NAC, SEC, SPC and cysteine on the activity of lipogenic-related enzymes is presented in Table 3. Compared to normal diet groups, the high-fat diet significantly elevated the activity of malic enzyme, FAS and HMG-CoA reductase. However, the intake of NAC, SEC or SPC significantly decreased high fat diet-elevated activity of malic enzyme, FAS and HMG-CoA reductase. The mRNA expression of malic enzyme, FAS and HMG-CoA reductase is shown in Fig. 1. When compared to normal diet groups, the high-fat diet significantly enhanced mRNA expression of

Table 2. TAG and total cholesterol (TC) concentrations in liver from mice treated with normal diet or high-fat diet with water, $n$-acetyl cysteine (NAC), s-ethyl cysteine (SEC), s-propyl cysteine (SPC) or cysteine (CYS)

(Mean values and standard deviations, $n$ 15)

\begin{tabular}{|c|c|c|c|c|}
\hline & \multicolumn{2}{|c|}{$\begin{array}{c}\text { TAG } \\
\text { (mg/g wet tissue) }\end{array}$} & \multicolumn{2}{|c|}{$\begin{array}{c}\text { TC } \\
\text { (mg/g wet tissue) }\end{array}$} \\
\hline & Mean & SD & Mean & SD \\
\hline \multicolumn{5}{|c|}{ Normal diet } \\
\hline Water & $30 \cdot 6^{\star}$ & $1 \cdot 8$ & $3 \cdot 2^{*}$ & 0.3 \\
\hline NAC & $31 \cdot 0^{*}$ & $1 \cdot 2$ & $3 \cdot 1^{*}$ & 0.6 \\
\hline SEC & $30 \cdot 4^{\star}$ & $1 \cdot 0$ & $2 \cdot 9^{*}$ & 0.5 \\
\hline SPC & $29 \cdot 6^{*}$ & 0.8 & $3 \cdot 0^{*}$ & 0.4 \\
\hline CYS & $31 \cdot 6^{*}$ & $2 \cdot 1$ & $3 \cdot 5^{\star}$ & 0.7 \\
\hline \multicolumn{5}{|c|}{ High-fat diet } \\
\hline Water & $50 \cdot 7 \dagger$ & $3 \cdot 0$ & $6.9 \dagger$ & 0.9 \\
\hline NAC & $43 \cdot 2^{*} \dagger$ & $2 \cdot 1$ & $4 \cdot 7^{\star} \dagger$ & 1.0 \\
\hline SEC & $38 \cdot 6^{\star} \dagger$ & $2 \cdot 9$ & $5 \cdot 1^{*} \dagger$ & 0.6 \\
\hline SPC & $41 \cdot 3^{*} \dagger$ & $2 \cdot 2$ & $4 \cdot 6^{*} \dagger$ & 0.8 \\
\hline CYS & $57 \cdot 4^{*} \dagger$ & $3 \cdot 1$ & $7.0 \dagger$ & 0.5 \\
\hline
\end{tabular}

Mean values were significantly different from those of the high-fat diet with water group: ${ }^{*} P<0.05$

Mean values were significantly different from those of the normal diet with water group: $\uparrow P<0.05$. 
Table 3. Activity of malic enzyme, fatty acid synthase (FAS) and 3-hydroxy-3-methylglutaryl coenzyme A (HMG-CoA reductase) in liver from mice treated with normal diet or high-fat diet with water, $n$-acetyl cysteine (NAC), s-ethyl cysteine (SEC), s-propyl cysteine (SPC) or cysteine (CYS)

(Mean values and standard deviations, $n$ 15)

\begin{tabular}{|c|c|c|c|c|c|c|}
\hline & \multicolumn{2}{|c|}{$\begin{array}{c}\text { Malic enzyme } \\
\text { (nmol/min per } \\
\text { mg protein) }\end{array}$} & \multicolumn{2}{|c|}{$\begin{array}{c}\text { FAS } \\
(\mathrm{nmol} / \mathrm{min} \\
\text { per } \mathrm{mg} \\
\text { protein) }\end{array}$} & \multicolumn{2}{|c|}{$\begin{array}{l}\text { HMG-CoA } \\
\text { reductase } \\
\text { (pmol/min per } \\
\text { mg protein) }\end{array}$} \\
\hline & Mean & SD & Mean & SD & Mean & SD \\
\hline \multicolumn{7}{|c|}{ Normal diet } \\
\hline Water & $3 \cdot 2^{*}$ & 0.4 & $2 \cdot 3^{*}$ & 0.6 & $21 \cdot 0^{*}$ & $1 \cdot 1$ \\
\hline NAC & $2 \cdot 8^{*}$ & 0.5 & $2 \cdot 4^{*}$ & 0.3 & $20 \cdot 3^{\star}$ & $1 \cdot 3$ \\
\hline SEC & $3 \cdot 0^{*}$ & 0.2 & $2 \cdot 0^{*}$ & 0.5 & $20 \cdot 1^{*}$ & 0.9 \\
\hline SPC & $2 \cdot 9^{\star}$ & 0.3 & $2 \cdot 1^{*}$ & 0.2 & $20 \cdot 5^{\star}$ & $1 \cdot 2$ \\
\hline CYS & $3 \cdot 5^{\star}$ & 0.6 & $2 \cdot 7^{\star}$ & 0.7 & $22 \cdot 8^{*}$ & 1.5 \\
\hline \multicolumn{7}{|c|}{ High-fat diet } \\
\hline Water & $5.4 \dagger$ & 0.8 & $5.4 \dagger$ & 0.4 & $34.3 \dagger$ & 1.0 \\
\hline NAC & $4 \cdot 2^{*} \dagger$ & 0.8 & $3 \cdot 5^{*} \dagger$ & 0.8 & $25 \cdot 8^{*} \dagger$ & 1.0 \\
\hline SEC & $3.9^{*} \dagger$ & 0.7 & $3.4^{*} \dagger$ & 0.4 & $26 \cdot 7^{\star} \dagger$ & 0.8 \\
\hline SPC & $4 \cdot 0^{\star} \dagger$ & 0.9 & $3 \cdot 8^{\star} \dagger$ & 0.5 & $27 \cdot 5^{\star} \dagger$ & $1 \cdot 2$ \\
\hline CYS & $5 \cdot 7 \dagger$ & 1.0 & $6 \cdot 8^{*} \dagger$ & 0.7 & $33.6 \dagger$ & 1.4 \\
\hline
\end{tabular}

Mean values were significantly different from those of the high-fat diet with water group: * $P<0.05$.

Mean values were significantly different from those of the normal diet with water group: $\dagger P<0.05$.

malic enzyme, FAS and HMG-CoA reductase, and the intake of NAC, SEC or SPC significantly suppressed high fatinduced mRNA expression of these three lipogenic-related enzymes. The mRNA expression of SREBP-1a, SREBP-1c and SREBP-2 is shown in Fig. 2. Compared to normal diet groups, the high-fat diet significantly elevated mRNA expression of these three proteins. NAC, SEC or SPC treatment significantly suppressed high fat-induced mRNA expression of SREBP-1c and SREBP-2 in liver $(P<0.05)$, but did not affect the expression of SREBP-1a $(P>0.05)$. The correlation coefficients between activity of three lipogenic-related enzymes and mRNA expression of these enzymes or SREBP are presented in Table 4. The activity of each enzyme was highly correlated with its mRNA expression because $r$ values were higher than $0 \cdot 7$. The correlation coefficients between SREBP-1c mRNA expression and the activity of malic enzyme or FAS were 0.627 and 0.728, respectively. The correlation coefficient between SREBP-2 mRNA expression and HMG-CoA reductase activity was 0.764 .

When mice consumed normal diet, the intake of NAC, SEC, SPC and cysteine significantly increased hepatic GSH content (Table 5); however, the intake of these compounds did not affect the activity of catalase and GPx $(P>0.05)$. Compared to normal diet groups, the high-fat diet decreased hepatic content of GSH, diminished the activity of catalase and GPx, and elevated oxidative stress, determined as malondialdehyde level $(P<0.05)$. The presence of NAC, SEC or SPC with the high-fat diet significantly increased hepatic GSH content when compared to the high-fat diet with water group. NAC, SEC and SPC intake also significantly restored the activity of GPx, and decreased malondialdehyde level. The mRNA expression of catalase and GPx is shown in Fig. 3. When compared to normal diet groups, the high-fat diet significantly suppressed the mRNA expression of catalase and GPx. However, the intake of NAC, SEC or SPC with the high-fat diet significantly up-regulated the expression of GPx when compared to the high-fat diet with water group. The correlation coefficients were 0.741 and 0.685 for catalase activity $v$. catalase mRNA expression, and GPx activity $v$. GPx mRNA expression. However, the correlation between catalase activity $v$. GPx mRNA expression, and GPx activity $v$. catalase mRNA expression were $0 \cdot 218$ and 0.197 .

Compared to the high-fat diet with water group, cysteine intake significantly increased hepatic TAG content $(P<0.05$; Table 2$)$, elevated FAS activity $(P<0 \cdot 05$; Table 3$)$, enhanced high fat-induced expression of SREBP-1c and SREBP-2 in liver $(P<0.05$; Fig. 2$)$, decreased activity and mRNA expression of catalase, and increased malondialdehyde level $(P<0.05$; Table 5; Fig. 3).

\section{Discussion}

Our previous study observed that a high-saturated fat diet prepared from coconut oil increased hepatic content of TAG and cholesterol in mice ${ }^{3}$. The results from the present study agreed

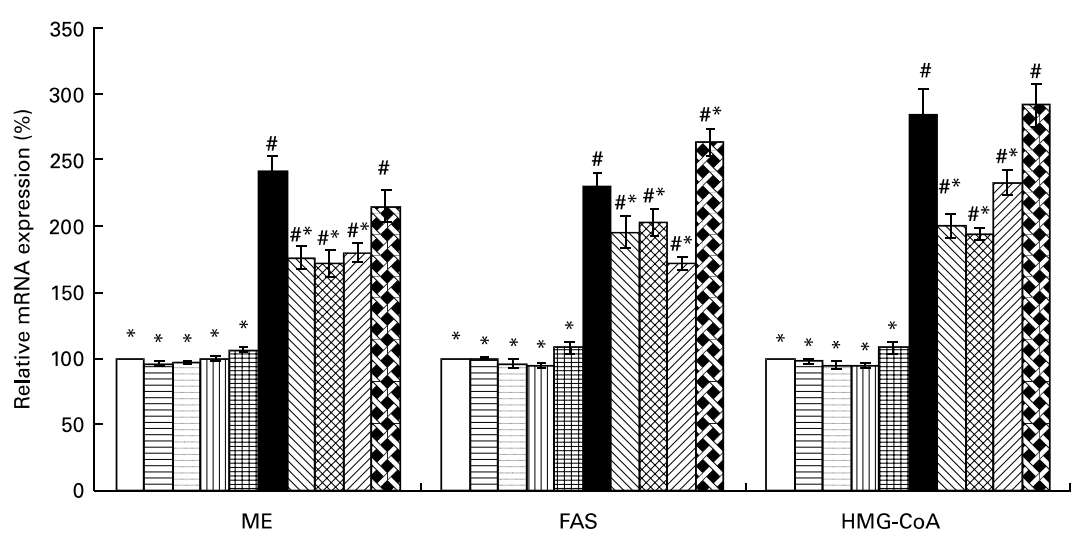

Fig. 1. The mRNA expression of malic enzyme (ME), fatty acid synthase (FAS) and 3-hydroxy-3-methylglutaryl coenzyme A (HMG-CoA) reductase in liver from mice treated with normal diet (control, $\square$ ) with $n$-acetyl cysteine $(\square)$, s-ethyl cysteine $(\square)$, s-propyl cysteine ( $\square$ ) or cysteine (畻); or high-fat diet with water ( $\square$ ), $n$-acetyl cysteine $(\mathbb{\nabla})$, s-ethyl cysteine (図), s-propyl cysteine $(\emptyset)$ or cysteine (圂). Values are means with their standard deviations depicted by vertical bars ( $n$ 15). Mean values were significantly different from those of the high-fat diet with water group: ${ }^{\star} P<0 \cdot 05$. Mean values were significantly different from those of the control group: $\# P<0.05$. 


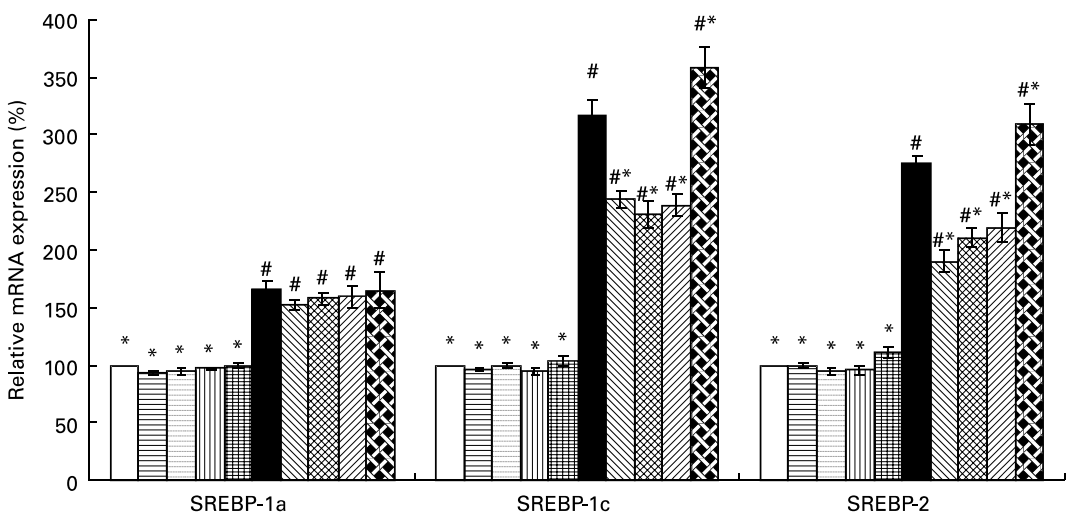

Fig. 2. The mRNA expression of sterol regulatory element-binding proteins (SREBP), SREBP-1a, SREBP-1c and SREBP-2 in liver from mice with normal diet

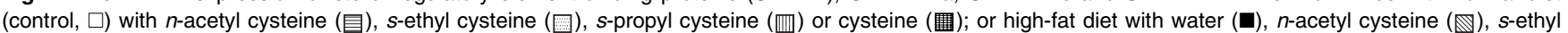
cysteine (圆), s-propyl cysteine (四) or cysteine (国). Values are means with their standard deviations depicted by vertical bars $(n 15)$. Mean values were significantly different from those of the high-fat diet with water group: ${ }^{\star} P<0.05$. Mean values were significantly different from those of the control group: \#P<0.05.

with our previous study because the diet used for the present study provided $55 \%$ saturated fat, and caused marked TAG and TC accumulation in liver. Furthermore, we found that the high-saturated fat diet enhanced the activity and mRNA expression of three enzymes participating in hepatic biosynthesis of TAG and cholesterol in liver, which partially explained the observed elevated hepatic TAG and cholesterol accumulation. On the other hand, the suppressive effects from NAC, SEC and SPC on the activity and mRNA expression of malic enzyme, FAS and HMG-CoA reductase also partially explained the lipid-lowering action of these agents.

It has been reported that SREBP could activate genes coding for enzymes involved in the biosynthesis of fatty acids and cholesterol via binding to sterol regulatory elements in their promoters, and the target genes of SREBP involved in TAG or cholesterol metabolism included FAS and HMG-CoA reductase $^{18,19}$. The present SREBP results found that the high-saturated fat diet markedly enhanced hepatic mRNA expression of SREBP-1c and SREBP-2, which may consequently activate mRNA expression, and elevate the activity of the three test lipogenic-related enzymes, and finally increase hepatic biosynthesis of TAG and cholesterol. It has been indicated that SREBP-1c is more effective in modulating the expression of genes involved in fatty acid synthesis, whereas SREBP-2 is predominant in regulating genes

Table 4. Correlation coefficients between the activity of malic enzyme, fatty acid synthase (FAS) and 3-hydroxy-3-methylglutaryl coenzyme A (HMG-CoA) reductase, and the mRNA expression of these enzymes and sterol regulatory element-binding proteins (SREBP), SREBP-1a, SREBP-1c and SREBP-2

\begin{tabular}{lccc}
\hline & \multicolumn{3}{c}{ Enzyme activity } \\
\cline { 2 - 4 } mRNA expression & Malic enzyme & FAS & HMG-CoA reductase \\
\hline Malic enzyme & $0.776^{*}$ & 0.335 & 0.176 \\
FAS & 0.364 & 0.804 & 0.204 \\
HMG-CoA reductase & 0.160 & 0.251 & 0.798 \\
SREBP-1a & 0.162 & 0.223 & 0.184 \\
SREBP-1c & 0.627 & 0.728 & 0.362 \\
SREBP-2 & 0.283 & 0.349 & 0.764
\end{tabular}

${ }^{*} P<0.05$ associated with cholesterol synthesis ${ }^{5,6}$. The correlation analyses also revealed that mRNA expression of SREBP-1c was highly correlated with the activity of FAS, and SREBP-2 mRNA expression was highly correlated with HMG-CoA reductase activity. Therefore, the results from the present study agreed that SREBP-1c and SREBP-2 were predominant in affecting the biosynthesis of fatty acids and cholesterol, respectively. Furthermore, we found the lipid-lowering action of NAC, SEC or SPC could be partially ascribed to suppress high saturated fat-induced up-regulation of SREBP-1c and SREBP-2. Consequently, the reduced SREBP-1c and SREBP-2 further diminished the expression of test lipogenic-related enzymes, and finally decreased TAG and cholesterol accumulation in liver. The present findings suggested that NAC, SEC and SPC were potent agents for suppressing saturated fat-induced hepatic biosynthesis of TAG and cholesterol.

Our previous study already found that a high-saturated fat diet impaired antioxidant defence via decreasing GPx activity $^{3}$. The results of the present study further indicated that a high-saturated fat diet decreased hepatic GSH content, and suppressed the activity and mRNA expression of catalase and GPx, which definitely contributed to the loss of antioxidant defence. It has been reported that cysteine-containing compounds could be converted to $\mathrm{GSH}^{20,21}$. The results from the present study agreed those previous studies because the intake of these agents increased hepatic GSH content. Furthermore, we found NAC, SEC and SPC could elevate mRNA expression of GPx, which also contributed to enhance antioxidative protection. Thus, the results of the present study implied that NAC, SEC and SPC could ameliorate high saturated fat diet-induced hepatic oxidative damage.

The presence of cysteine with high saturated fat markedly enhanced the mRNA expression of FAS, SREPB-1c and SREBP-2 in liver, which partially explained why this agent enhanced the biosynthesis of TAG and cholesterol. Although the intake of cysteine also restored hepatic GSH content, this agent failed to up-regulate GPx mRNA expression, and even suppressed the mRNA expression of catalase. Finally, the overall antioxidant defence markedly decreased. The present results suggest that cysteine with a high-saturated fat diet favoured the development of fatty liver-related diseases or hepatic oxidative-associated diseases. 
Table 5. Malondialdehyde (MDA) concentration, glutathione (GSH) content, catalase activity and glutathione peroxidase (GPx) activity in liver from mice treated with normal diet or high-fat diet with water, $n$ acetyl cysteine (NAC), s-ethyl cysteine (SEC), s-propyl cysteine (SPC) or cysteine (CYS)

(Mean values and standard deviations, $n$ 15)

\begin{tabular}{|c|c|c|c|c|c|c|c|c|}
\hline & \multicolumn{2}{|c|}{$\begin{array}{l}\text { MDA (nmol/mg } \\
\text { protein) }\end{array}$} & \multicolumn{2}{|c|}{$\begin{array}{l}\mathrm{GSH}(\mathrm{nmol} / \mathrm{mg} \\
\text { protein) }\end{array}$} & \multicolumn{2}{|c|}{$\begin{array}{l}\text { Catalase activity } \\
\text { (U/mg protein) }\end{array}$} & \multicolumn{2}{|c|}{$\begin{array}{c}\text { GPx activity } \\
\text { (U/mg protein) }\end{array}$} \\
\hline & Mean & SD & Mean & SD & Mean & SD & Mean & SD \\
\hline \multicolumn{9}{|c|}{ Normal diet } \\
\hline Water & $0.58^{\star}$ & 0.14 & $19 \cdot 3^{\star}$ & 1.0 & $41.0^{*}$ & 1.3 & $34 \cdot 2^{*}$ & $2 \cdot 3$ \\
\hline NAC & $0.53^{\star}$ & 0.15 & $23 \cdot 3^{*} \dagger$ & 1.3 & $40 \cdot 6^{*}$ & 1.1 & $34.7^{*}$ & $2 \cdot 0$ \\
\hline SEC & $0.60^{*}$ & 0.20 & $22 \cdot 4^{*} \dagger$ & 1.8 & $41 \cdot 3^{*}$ & 0.9 & $35 \cdot 6^{*}$ & 1.8 \\
\hline SPC & $0.54^{*}$ & 0.17 & $23 \cdot 7^{*} \dagger$ & 1.7 & $40 \cdot 8^{*}$ & 1.2 & $34.1^{*}$ & 2.5 \\
\hline CYS & $0.55^{\star}$ & 0.12 & $23 \cdot 1^{*} \dagger$ & 1.5 & $40.5^{\star}$ & 1.0 & $35.0^{*}$ & 1.7 \\
\hline \multicolumn{9}{|c|}{ High-fat diet } \\
\hline Water & $1.41 \dagger$ & 0.28 & $11.5 \dagger$ & 1.0 & $27.0 \dagger$ & $2 \cdot 6$ & $20.4 \dagger$ & 1.8 \\
\hline NAC & $0.90^{*} \dagger$ & 0.12 & $19 \cdot 1^{*}$ & 0.8 & $29.0 \dagger$ & 1.3 & $29 \cdot 7^{*} \dagger$ & 1.6 \\
\hline SEC & $0.94^{*} \dagger$ & 0.16 & $18 \cdot 7^{\star}$ & 0.6 & $29.4 \dagger$ & 1.8 & $28 \cdot 6^{*} \dagger$ & $2 \cdot 4$ \\
\hline SPC & $0.86^{*} \dagger$ & 0.10 & $16 \cdot 8^{*} \dagger$ & 0.9 & $28.6 \dagger$ & 2.0 & $30.5^{\star} \dagger$ & 1.9 \\
\hline CYS & $1.83^{*} \dagger$ & 0.25 & $13 \cdot 9^{*} \dagger$ & 1.3 & $21 \cdot 3^{*} \dagger$ & 1.7 & $21 \cdot 7 \dagger$ & $2 \cdot 0$ \\
\hline
\end{tabular}

Mean values were significantly different from those of the high-fat diet with water group: ${ }^{*} P<0.05$. Mean values were significantly different from those of the normal diet with water group: $† P<0.05$.

The three test compounds used in the present study are hydrophilic peptide derivates, and naturally formed in Allium foods such as garlic; however, the protection from these agents was different. Apparently, the ethyl group of SEC and the propyl group of SPC played important roles in determining their bioactivities. Krest et ll. $^{22}$ reported that the content of organosulphur compounds from Allium plants was dependent on the species or vegetation period. Thus, it may not be appropriate to obtain these compounds by directly consuming garlic or other Allium plants.

In conclusion, a high-saturated fat diet enhanced lipid biosynthesis via enhancing the activity and mRNA expression of lipogenic-related enzymes and SREBP in liver; the intake of NAC, SEC or SPC effectively suppressed the activity and mRNA expression of lipogenic-related enzymes and SREBP, and contributed to decreased TAG and cholesterol accumulation in liver. The intake of these agents also ameliorated high saturated fat-induced oxidative stress in liver via increasing GSH content, and elevated the activity and mRNA

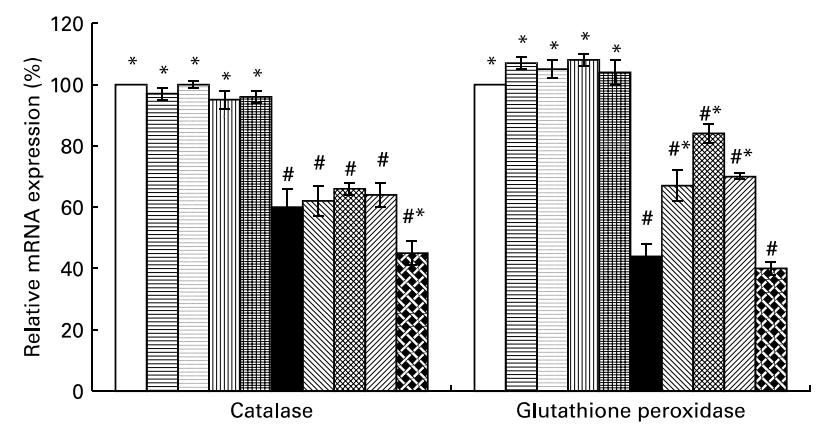

Fig. 3. The mRNA expression of catalase and glutathione peroxidase in liver from mice treated with normal diet (control, $\square$ ) with $n$-acetyl cysteine ( $\square$ ), s-ethyl cysteine $(\square)$, s-propyl cysteine $(\square)$ or cysteine (㲘); or high-fat diet with water $(\mathbf{\square}), n$-acetyl cysteine $(\mathbb{\nabla})$, s-ethyl cysteine (図), $s$-propyl cysteine (曰) or cysteine (圂). Values are means with their standard deviations depicted by vertical bars ( $n$ 15). Mean values were significantly different from those of the high-fat diet with water group: ${ }^{\star} P<0.05$. Mean values were significantly different from those of the control group: \#P<0.05. expression of GPx. The present results support that NAC, SEC and SPC are potent agents for hepatic protection against high saturated fat-associated diseases.

\section{Acknowledgements}

This study was supported by a grant from the National Science Council, ROC (NSC 95-2320-B-024-MY2). The authors thank Wakunaga Pharmaceutical Co. Ltd (Hiroshima, Japan) for kindly supplying SPC.

\section{References}

1. Fukushima S, Takada N, Hori T \& Wanibuchi H (1997) Cancer prevention by organosulfur compounds from garlic and onion. J Cell Biochem 27, Suppl., 100-105.

2. Jones MG, Hughes J, Tregova A, Milne J, Tomsett AB \& Collin HA (2004) Biosynthesis of the flavour precursors of onion and garlic. J Exp Bot 55, 1903-1918.

3. Lin CC, Yin MC, Hsu CC \& Lin MP (2004) Effect of five cysteinecontaining compounds on three lipogenic enzymes in Balb/cA mice consuming a high saturated fat diet. Lipids 39, 843-848.

4. Shimano H, Yahagi N, Amemiya-Kudo M, Hasty AH, Osuga J, Tamura Y, Shionoiri F, Iizuka Y, Ohashi K, Harada K, Gotoda T, Ishibash S \& Yamada N (1999) Sterol regulatory elementbinding protein-1 as a key transcription factor for nutritional induction of lipogenic enzyme genes. $J$ Biol Chem 274, 35832-35839.

5. Shimomura I, Shimano H, Horton JD, Goldstein JL \& Brown MS (1997) Differential expression of exons 1a and 1c in mRNAs for sterol regulatory element binding protein-1 in human and mouse organs and cultured cells. J Clin Invest 99, 838-845.

6. Horton JD, Shimomura I, Brown MS, Hammer RE, Goldstein JL \& Shimano H (1998) Activation of cholesterol synthesis in preference to fatty acid synthesis in liver and adipose tissue of transgenic mice overproducing sterol regulatory element-binding protein-2. J Clin Invest 101, 2331-2339.

7. Jacob N, Bruckert E, Giral P, Foglietti MJ \& Turpin G (1999) Cysteine is a cardiovascular risk factor in hyperlipidemic patients. Atherosclerosis 146, 53-59. 
8. Ozkan Y, Ozkan E \& Simsek B (2002) Plasma total homocysteine and cysteine levels as cardiovascular risk factors in coronary heart disease. Int J Cardiol 82, 269-277.

9. Lowry OH, Rosebrough NJ, Farr AL \& Randall RJ (1951) Protein determination with the Folin phenol reagent. J Biol Chem 193, 265-275.

10. Miura Y, Hosono M, Oyamada C, Odai H, Oikawa S \& Kondo K (2005) Dietary isohumulones, the bitter components of beer, raise plasma HDL-cholesterol levels and reduce liver cholesterol and triacylglycerol contents similar to PPARalpha activations in C57BL/6 mice. $\mathrm{Br} J$ Nutr 93, 559-567.

11. Stelmanska E, Korczynska J \& Swierczynski J (2004) Tissuespecific effect of refeeding after short- and long-term caloric restriction on malic enzyme gene expression in rat tissues. Acta Biochim Pol 51, 805-814.

12. Nepokroeff CM, Lakshmanan MR \& Porter JW (1975) Fattyacid synthase from rat liver. Methods Enzymol 35, 37-44.

13. Kita T, Brown MS \& Goldstein JL (1980) Feedback regulation of 3-hydroxy-3-methylglutaryl coenzyme A reductase in livers of mice treated with mevinolin, a competitive inhibitor of the reductase. J Clin Invest 66, 1094-1100.

14. Jain SK \& Palmer M (1997) The effect of oxygen radical metabolites and vitamin $\mathrm{E}$ on glycosylation or proteins. Free Radic Biol Med 22, 593-596.

15. Kim HJ, Takahashi M \& Ezaki O (1999) Fish oil feeding decreases mature sterol regulatory element-binding protein 1
(SREBP-1) by down-regulation of SREBP-1c mRNA in mouse liver. A possible mechanism for down-regulation of lipogenic enzyme mRNAs. J Biol Chem 274, 25892-25898.

16. Yu XX, Murray SF, Pandey SK, Booten SL, Bao D, Spng XZ, Kelly S, Chen S, McKay R, Monia BP \& Bhanot (2005) Antisense oligonucleotide reduction of DGAT2 expression improves hepatic steatosis and hyperlipidemia in obese mice. Hepatology 42, 362-371.

17. Song LH, Yan HL \& Cai DL (2006) Protective effects of isoflavone against gamma-irradiation induced damages in mice. $J$ Radiat Res 47, 157-165.

18. Magana MM \& Osborne TF (1996) Two tandem binding sites for sterol regulatory element binding proteins are required for sterol regulation of fatty-acid synthase promoter. J Biol Chem 271, 32689-32694.

19. Brown MS \& Goldstein JL (1997) The SREBP pathway: regulation of cholesterol metabolism by proteolysis of a membrane-bound transcription factor. Cell 89, 331-340.

20. Hsu CC, Yen HF, Yin MC, Tsai CM \& Hsieh CH (2004) Five cysteine-containing compounds delay diabetic deterioration in Balb/cA mice. J Nutr 134, 3245-3249.

21. Hsu CC, Lin CC, Liao TS \& Yin MC (2006) Protective effect of s-allyl cysteine and s-propyl cysteine on acetaminophen-induced hepatotoxicity in mice. Food Chem Toxicol 44, 393-397.

22. Krest I, Glodek J \& Keusgen M (2000) Cysteine sulfoxides and allinase activity of some Allium species. J Agric Food Chem 48, $3753-3760$ 